\title{
The rs822396 Polymorphism of the ADIPOQ Gene Is Associated with Anthropometric, Clinical, and Biochemical Alterations Related to the Metabolic Syndrome in the Mexican Population
}

\author{
Lidia Ariadna Rubio-Chavez, MsD, ${ }^{1}$ Roberto Carlos Rosales-Gomez, PhD, ${ }^{2}$ \\ Keren-Hapuc Lilian Rubio-Chavez, BchD, Julia Leonila Ramos-Nuñez, PhD, ${ }^{1}$ \\ Teresa Arcelia Garcia-Cobian, PhD, ${ }^{1}$ Gabriela Camargo-Hernandez, PhD, ${ }^{3}$ \\ Jose Sanchez-Corona, MD, PhD, ${ }^{4}$ and Susan Andrea Gutierrez-Rubio, $\mathrm{PhD}^{1}$
}

\begin{abstract}
Background: Adiponectin, encoded by the $A D I P O Q$ gene, is produced mainly by adipose tissue, and meaning as a metabolic and immunological regulator. The polymorphism rs822396 in ADIPOQ gene was previously associated with diabetes mellitus type 2, hypertension, and metabolic syndrome components in Caucasian and Asiatic populations. The aim was to evaluate the association of the rs822396 polymorphism of the ADIPOQ gene with anthropometric, clinical, and biochemical alterations related to the metabolic syndrome in the Mexican population. Materials and Methods: Measurements, as well as peripheral blood for DNA extraction, were obtained from 434 participants from Mexico. The rs822396 polymorphism genotyping was performed by polymerase chain reaction-restriction fragment length polymorphism. Statistical analysis was made with IBM-SPSSv20.

Results: The rs $822396 \mathrm{G}$ allele frequency was $22.1 \%$ in the Mexican population analyzed. In this study were detected differences according to $\mathrm{G}$ allele or GG genotype with the highest means, including body mass index (BMI), waist circumference (WC), body fat percentage, visceral fat, systolic arterial tension, glucose levels, triglyceride levels, total cholesterol (TC) levels, very low-density lipoprotein, alanine aminotransferase, and aspartate aminotransferase and with triglycerides/glucose index. Significant differences were found with increased risk in the dominant model (AG/GG) of anthropometric, clinical, and biochemical alterations with regard to metabolic syndrome as the BMI [odds ratio $(\mathrm{OR})=2.19$ ], $\mathrm{WC}(\mathrm{OR}=2.00)$, waist/hip index $(\mathrm{OR}=1.65)$, body fat percentage $(\mathrm{OR}=2.76)$, visceral fat $(\mathrm{OR}=1.84)$, glucose levels $(\mathrm{OR}=1.95)$, triglyceride levels $(\mathrm{OR}=2.75)$, TC levels $(\mathrm{OR}=1.63)$, high-density lipoprotein $(\mathrm{OR}=1.86)$, and insulin resistance surrogated by the Triglyceride/glucose index $(\mathrm{OR}=2.64)$.

Conclusion: The rs822396 polymorphism of the ADIPOQ gene seems to be a risk factor for obesity and metabolic alterations with regard to the metabolic syndrome in the Mexican population.
\end{abstract}

Keywords: adiponectin, $A D I P O Q$, polymorphism, metabolic syndrome

\section{Introduction}

I

N MeXiCo AND WORLDWIDE, due to the increase in incidence and deaths caused by chronic diseases such as obesity, diabetes mellitus type 2 (DM2), dyslipidemias, and cardiac diseases, among others, studies have focused on the analysis of adipose tissue participation in these pathologies. The white adipose tissue, in addition to storing energy, has endocrine function, through the secretion of adipokines, which regulate metabolic and immunological mechanisms, both observed in the development process of chronic diseases. ${ }^{1}$

\footnotetext{
${ }^{1}$ Laboratorio del Instituto de Terapeutica Experimental y Clinica, Departamento de Fisiologia, Centro Universitario de Ciencias de la Salud, Universidad de Guadalajara, Guadalajara, México.

${ }^{2}$ Departamento de Ciencias Biomedicas, Centro Universitario de Tonala, Universidad de Guadalajara, Tonala, México.

${ }^{3}$ Departamento de Ciencias de la Salud, Centro Universitario de los Altos, Universidad de Guadalajara, Tepatitlan, México.

${ }^{4}$ Division de Medicina Molecular, Centro de Investigacion Biomedica del Occidente, IMSS Instituto Mexicano del Seguro Social, Guadalajara, México.
} 
Adiponectin (ApN) is synthesized mainly by adipocytes. The ApN of $30 \mathrm{kDa}$ is related to the regulation of energy and homeostasis in addition to the metabolism of carbohydrates and lipids. $^{2,3}$ The ApN, encoded by the $A D I P O Q$ gene (ID: 9370), is located in 3q27 and consists of three coding exons. ${ }^{4}$ The rs 822396 polymorphism is a change of adenine by guanine at position -3971 in intron 1 of the $A D I P O Q$ gene. The intron 1 contains a region with a response element to the ccaat/enhancer-binding protein beta (C/EBP) factor ${ }^{5}$ nearly to rs822396 polymorphism, thus the polymorphism could participate in the transcriptional regulation of $A D I$ $P O Q$ by the C/EBP factor. Several studies in the Caucasian and Asian population have demonstrated an association of the GG genotype of the polymorphism rs822396 with an increased risk for incidence of DM2, abdominal obesity, increase in body mass index (BMI), and increase in fasting total cholesterol (TC). ${ }^{6-8}$

The aim of this work was to evaluate the association of genotypic and allelic frequencies of rs822396 polymorphism in the $A D I P O Q$ gene with the anthropometric, clinical, and biochemical alterations related to the metabolic syndrome in the Mexican population.

\section{Materials and Methods}

\section{Participants}

A cross-sectional study was conducted with 434 participants who attended the Institute of Experimental and Clinical Therapeutics (INTEC) at the University Center of Health Sciences of the University of Guadalajara. The participants were older than 18 years old, both gender, from Mexico and signed an informed consent letter voluntarily following the guidelines of the Helsinki Declaration of Health.

The anthropometric and clinical data were collected from all participants and it was registered with an alphanumeric sequence for confidentiality. The measurements were taken as height, BMI, waist circumference (WC), and hip circumference (HC) (taken according to the International Society for the Advancement of Kinanthropometry [ISAK] method), in addition to weight, body fat percentage, muscle mass and visceral fat (by impedance, in Omron equipment model $\mathrm{Hbf}$ 514c), and blood pressure [systolic arterial tension (SAT) and diastolic arterial tension (DAT)] at three times, each spaced 2 min (Omron electronic equipment model HEM-7220).

\section{Biological samples and biochemical determinations}

A peripheral blood volume of $10 \mathrm{~mL}$, in fasting, was taken from the participants to obtain serum and DNA. Serum biochemical determinations were glucose (ref. 11538), uric acid (ref. 11521), creatinine (ref. 11802), alanine aminotransferase (ALT; ref. 11533), aspartate aminotransferase (AST; ref. 11531), and lipid profile, including TC (ref. 11505), triglycerides, high-density lipoprotein (HDL; ref. 115557), and low-density lipoprotein (LDL; ref. 11585), with the BioSystems Kits (Biosystems S.A., Barcelona, Spain), using the ERBA X-100 equipment. To determine insulin resistance (IR), the triglyceride/glucose index (T/G index) calculation was used in substitution of the homeostatic model assessment (HOMA) index, as previously described. ${ }^{9}$

DNA isolation was performed by the salt precipitation method $^{10}$ from whole blood anticoagulated with EDTA. The quantification of the nucleic acid was performed in Nano-
Drop 2000 (model ND-2000; Thermo Fisher Scientific, Wilmington, DE), and a working dilution was prepared at $100 \mathrm{ng} / \mu \mathrm{L}$. The samples were stored at $-20^{\circ} \mathrm{C}$ until use.

\section{Molecular determinations}

The polymerase chain reaction (PCR) primers for the determination of the polymorphism rs822396 were designed in the Primer3 program. The PCR was achieved with a reaction mixture containing $100 \mathrm{ng}$ of DNA, $1 \times$ of buffer (20 mM of Tris- $\mathrm{mCl}, \mathrm{pH} 8.4,50 \mathrm{mM}$ of $\mathrm{KCl}$ ), $2 \mathrm{mM}$ of $\mathrm{MgCl}_{2}, 0.2 \mathrm{mM}$ of dNTPs, $5 \mathrm{pM}$ of the primers $\mathrm{F}-5^{\prime}-\mathrm{ggT}$ CTT ggA AAC TTC TgA ggC T-3' and R-5'-AAA CCT Tgg AgA gAg ggC AA-3,' as well as $0.1 \mathrm{U}$ of Taq polymerase (cat.11615-010; Invitrogen ${ }^{\circledR}$; Life Technologies Corporation, Carlsbad, CA). The PCR was performed with an initial temperature of $94^{\circ} \mathrm{C}$ for $3 \mathrm{~min}$, with 35 cycles at $94^{\circ} \mathrm{C}$ for $20 \mathrm{sec}, 60^{\circ} \mathrm{C}$ for $30 \mathrm{sec}, 72^{\circ} \mathrm{C}$ for $30 \mathrm{sec}$, and finally the final step of $72^{\circ} \mathrm{C}$ for $10 \mathrm{~min}$ to obtain an amplified product of $245 \mathrm{bp}$. The identification of the genotypes by restriction fragment length polymorphism was with the MseI enzyme (ref. R0525; New England Biolabs ${ }^{\circledR}$, Ipswich, MA), where the allele A generates two fragments of $181+64 \mathrm{bp}$. The hydrolysis reaction contained $5 \mu \mathrm{L}$ of PCR product, one unit of restriction enzyme, and $1 \times$ of $\mathrm{CutSmart}^{\circledR}$ buffer ( $50 \mathrm{mM}$ of potassium acetate, $20 \mathrm{mM}$ of Tris-acetate, $10 \mathrm{mM}$ magnesium acetate, $0.1 \mathrm{mg} / \mathrm{mL}$ bovine serum albumin, $\mathrm{pH}$ 7.9 at $25^{\circ} \mathrm{C}$; New England Biolabs). The reaction was incubated for $1 \mathrm{hr}$ at $37^{\circ} \mathrm{C}$. The separation and visualization of the fragments were in $6 \%$ polyacrylamide gels $(29: 1)$ stained with silver nitrate.

\section{Statistical analysis}

The analysis was made in the IBM-SPSS v20 program. For qualitative and quantitative clinical and biochemical data, the comparisons were made with Student's $t$-test, analysis of variance (ANOVA), and Bonferroni for equal variances and when the variances were different with the Kruskal-Wallis and Mann-Whitney U test. We performed chi-squared test of the goodness of fit to determine the Hardy-Weinberg Equilibrium of the genotypes in the general population. The comparison of allelic and genotypic distributions was performed with chi-squared or Fisher's exact test and logistic regression for odds ratio (OR) calculation. The statistic power of the present study was $80 \%$ for a $95 \%$ confidence level.

\section{Results}

\section{Clinical and biochemical determinations}

The anthropometric and clinical parameters such as BMI, WC, HC, weight, body fat percentage, muscle mass and visceral fat, and blood pressure (SAT and DAT) were determined in the 434 studied participants. The overweight and obesity were observed in $66.2 \%$ of participants, and $69.2 \%$ had abdominal obesity (with a higher percentage in men); in addition, hypertension was detected in $36 \%$ of the individuals. The biochemical parameters in fasting, including glucose, uric acid, creatinine, ALT, AST, and lipid profile (TC, triglycerides, HDL, and LDL), were determined. Of the total individuals, $11.2 \%$ presented levels higher than $125 \mathrm{mg} / \mathrm{dL}$ of glucose in fasting. Furthermore, $37.3 \%$ of the participants 
had glucose levels greater than $100 \mathrm{mg} / \mathrm{dL}$. The $42.2 \%$ and $43.8 \%$ of the participants had altered triglycerides $(>150 \mathrm{mg} / \mathrm{dL})$ and TC $(>200 \mathrm{mg} / \mathrm{dL})$, respectively.

The participants were separated by gender counting 308 women $(71 \%)$ and 126 men (29\%) as described in Table 1. The means of the anthropometric and clinical characteristics were calculated and compared according to gender. It was found that men had higher means with regard to WC, muscle mass, visceral fat, and blood pressure, whereas women had higher body fat percentage mean.

The biochemical determinations are described in Table 2 . The average of the biochemical parameters was calculated and compared by gender. The men had the highest levels of triglycerides, very low-density lipoprotein (VLDL), uric acid, creatinine, and ALT, otherwise, women had elevated levels of TC and HDL.

\section{Surrogated IR}

The surrogated IR was determined by the formula T/G index $=\mathrm{Ln}$ [(fasting triglycerides, $\mathrm{mg} / \mathrm{dL} \times$ fasting glucose, $\mathrm{mg} / \mathrm{dL}) / 2$ ], in this way, a $\mathrm{T} / \mathrm{G}$ index $>4.68$ determines IR and $<4.68$ indicates no resistance to insulin. ${ }^{5,9}$ According to the last, IR was detected in $57.6 \%$ of the participants. Moreover, $55.3 \%$ of women and $63.3 \%$ of men with IR were identified. The means of individuals with IR $(4.9 \pm 0.26)$ and the individuals without IR $(4.4 \pm 0.17)$ were different statistically ( $P=0.000$, Mann-Whitney U test). According to gender, men had a higher mean of insulin resistance (IR) value than women (Table 2). Furthermore, the IR value average in men and women was altered.

\section{Polymorphism rs822396 association analysis}

The allelic and genotypic frequencies for the rs822396 polymorphism are in Hardy-Weinberg equilibrium $(P=0.668355)$. With a total of 424 genotyped participants, we obtained a frequency of $60.8 \%$ for the AA genotype, $33.9 \%$ for the AG heterozygotes, and 5.3\% for the GG genotype, as well as the frequencies of $77.9 \%$ for the A allele and $22.1 \%$ for the allele $\mathrm{G}$.

The muscle mass (0.647), TG (0.194), LDL (0.201), glucose $(0.168)$, and $T / G$ index were correlated to the genotype of the rs 822396 polymorphism. Further analysis for means of anthropometric, clinical, and biochemical characteristics by genotype was made (Table 3 ). It was observed that GG genotype carriers had the highest means in anthropometric parameters, including BMI, WC, body fat percentage, visceral fat, SAT, as well as biochemical values such as glucose levels, triglyceride levels, TC levels, VLDL, ALT, AST, and with T/G index. In contrast, the GG carriers had the lowest serum level with the HDL and LDL. In the case of creatinine, uric acid, ALT, HDL and LDL, body fat, and muscle and visceral fat, a number of participants did not have all data; however all genotypes are representative.

Table 4 contains the anthropometric, clinical, and biochemical values, making cut according to the International Diabetes Federation (IDF) guidelines ${ }^{11}$ of diagnostic criteria for the Metabolic Syndrome with regard to the rs 822396 polymorphism genotype, allele, and the dominant model. The analysis was adjusted by gender. The heterozygous genotype A/G showed an OR between 1.67 and 2.86 in altered factors related to overweight and obesity, as well as

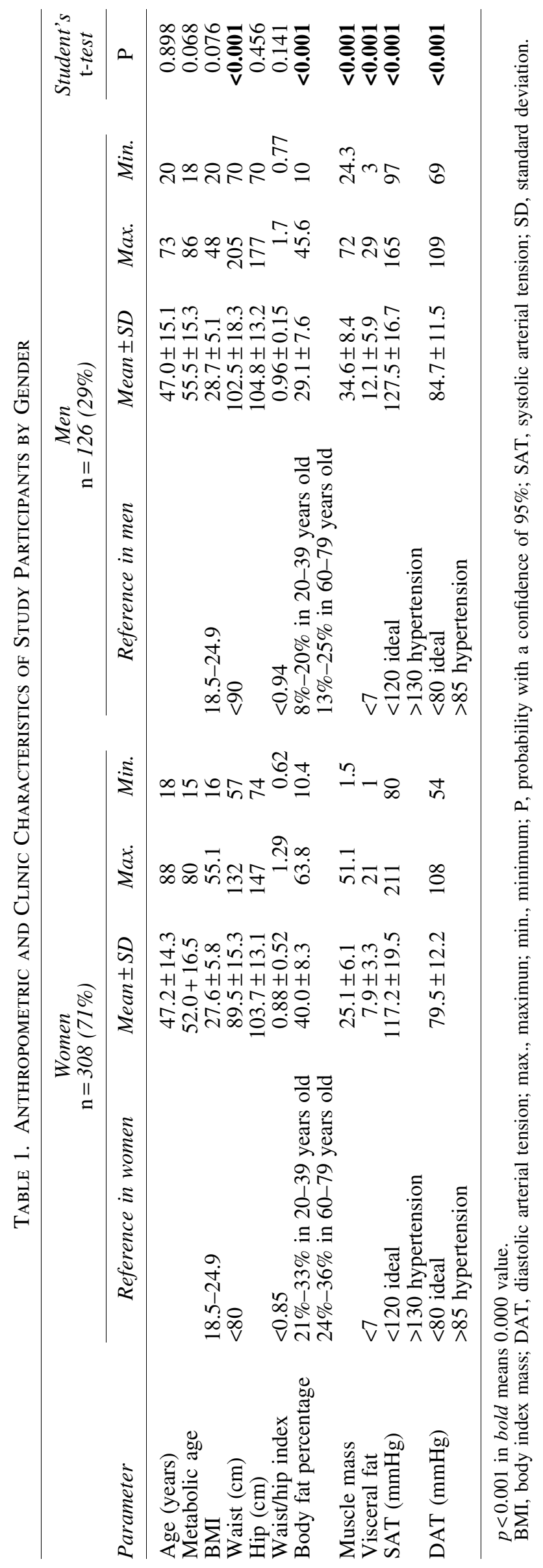


Table 2. Biochemical Data of Study Participants by Gender

\begin{tabular}{|c|c|c|c|c|c|c|c|c|c|}
\hline \multirow[b]{2}{*}{ Parameter } & \multicolumn{4}{|c|}{$\begin{aligned} & \text { Women } \\
\mathrm{n}= & 308(71 \%)\end{aligned}$} & \multicolumn{4}{|c|}{$\begin{array}{c}\text { Men } \\
\mathrm{n}=126(29 \%)\end{array}$} & \multirow{2}{*}{$\begin{array}{c}\begin{array}{c}\text { Student's } \\
\mathrm{t} \text {-test }\end{array} \\
\mathrm{P}\end{array}$} \\
\hline & $\begin{array}{l}\text { Reference } \\
\text { in women }\end{array}$ & Mean $\pm S D$ & Max. & Min. & $\begin{array}{l}\text { Reference } \\
\text { in men }\end{array}$ & $M e a n \pm S D$ & Max. & Min. & \\
\hline Glucose $(\mathrm{mg} / \mathrm{dL})$ & $<100$ & $103.5 \pm 46.3$ & 483.7 & 44.6 & $<100$ & $108.5 \pm 46.0$ & 315 & 67.4 & 0.315 \\
\hline Triglycerides (mg/dL) & 70-149 & $147.8 \pm 83.0$ & 601 & 31 & $70-149$ & $179.2 \pm 150.7$ & 1332 & 40 & 0.006 \\
\hline Total cholesterol $(\mathrm{mg} / \mathrm{dL})$ & 100-199 & $197.9 \pm 40.9$ & 322 & 106 & 100-199 & $185.5 \pm 35.3$ & 317 & 127 & 0.009 \\
\hline HDL (mg/dL) & $>50$ & $56.7 \pm 15.2$ & 97.1 & 32 & $>40$ & $45.8 \pm 9.48$ & 89.5 & 27.8 & $<0.001$ \\
\hline LDL (mg/dL) & $100-150$ & $110.9 \pm 37.8$ & 234 & 22 & $100-150$ & $103.2 \pm 32.4$ & 167 & 15.3 & 0.158 \\
\hline VLDL $(\mathrm{mg} / \mathrm{dL})$ & & $28.5 \pm 15$ & 60 & 6.2 & & $33.6 \pm 20.2$ & 60 & 8 & 0.020 \\
\hline Úric acid (mg/dL) & $2.4-6$ & $5.26 \pm 4.01$ & 9.03 & 2.61 & $3.4-7$ & $6.42 \pm 1.67$ & 11.31 & 3.45 & 0.004 \\
\hline Creatinine $(\mathrm{mg} / \mathrm{dL})$ & $0.6-1$ & $0.65 \pm 0.31$ & 4.1 & 0.14 & $0.7-1.2$ & $0.84 \pm 0.26$ & 1.74 & 0.38 & $<0.001$ \\
\hline ALT (IU/L) & $7-34$ & $19.0 \pm 12.4$ & 62.8 & 6 & $10-40$ & $24.7 \pm 14.0$ & 85 & 8 & 0.010 \\
\hline AST (IU/L) & $7-34$ & $23.9 \pm 10.3$ & 58.3 & 5.7 & $10-40$ & $27.2 \pm 9.48$ & 61.1 & 7.8 & 0.102 \\
\hline $\mathrm{T} / \mathrm{G}$ index & $<4.68$ & $4.72 \pm 0.35$ & 5.9 & 3.9 & $<4.68$ & $4.82 \pm 0.35$ & 6.0 & 4.0 & 0.010 \\
\hline
\end{tabular}

$p<0.001$ in bold means 0.000 value.

ALT, alanine aminotransferase; AST, aspartate aminotransferase; HDL, high-density lipoprotein; LDL, low-density lipoprotein; $\mathrm{P}$, probability with a confidence of $95 \%$; T/G index, triglyceride/glucose index; VLDL, very low-density lipoprotein.

metabolic alterations such as glucose levels, triglyceride levels, TC levels, and RI surrogated. The GG genotype was associated with a 2.61-fold risk to altered triglycerides. Likewise, some statistical differences were observed in the dominant model (carriers of $\mathrm{G}$ allele, AG/GG) and G Allele, with a range of OR between 1.63 and 2.76 in altered factors similar to AG genotype, as well as with waisthip index and LDL.

\section{Discussion}

The metabolic diseases are a health problem in Mexico since they represent the first places of mortality in adults older than 20 years. ${ }^{12}$ Obesity, besides being a metabolic disease, is also a risk factor for DM2, hypertension, dyslipidemias, and metabolic syndrome. ${ }^{13}$ In obesity, there is an expansion of adipose tissue, showing a metabolic dysregulation that leads to the alteration of the endocrine function of this tissue. ${ }^{13} \mathrm{ApN}$ participates in the metabolic regulation of the endocrine, paracrine, and autocrine trails. ${ }^{14}$ The decrease in serum ApN levels and $A D I P O Q$ polymorphisms is associated with obesity. In addition, low ApN levels lead to an inflammatory state and metabolic dysregulation. ${ }^{6,7,14-17}$ In the present study, we propose to evaluate the frequency of the polymorphism rs 822396 of the $A D I P O Q$ gene with respect to

Table 3. The Means of Clinical, Anthropometric, and Biochemical Parameters with Regard to the GenOtyPe OF RS822396 Polymorphism In the ADIPOQ GeNe

\begin{tabular}{|c|c|c|c|c|c|}
\hline \multirow[b]{2}{*}{ Parameter } & \multicolumn{3}{|c|}{ Polymorphism rs822396, mean \pm SD } & \multirow[b]{2}{*}{$\begin{array}{c}\text { Analysis } \\
\text { of variance }\end{array}$} & \multirow[b]{2}{*}{ Bonferron } \\
\hline & $\begin{array}{c}A A \\
\mathrm{n}=264(60.83 \%)\end{array}$ & $\begin{array}{c}A / G \\
\mathrm{n}=147(33.87 \%)\end{array}$ & $\begin{array}{c}G G \\
\mathrm{n}=23(5.30 \%)\end{array}$ & & \\
\hline BMI & $27.3 \pm 5.7$ & $28.5 \pm 5.0$ & $30.4 \pm 7.31$ & $<0.001$ & 1,2 \\
\hline Waist $(\mathrm{cm})$ & $91.4 \pm 18.2$ & $95.4 \pm 13.4$ & $100.0 \pm 14.3$ & $<0.001^{a}$ & $1^{\mathrm{a}}, 2^{\mathrm{a}}$ \\
\hline Hip $(\mathrm{cm})$ & $103.7 \pm 12.4$ & $104.9 \pm 9.89$ & $105.8 \pm 19.9$ & 0.325 & \\
\hline Waist/hip index & $0.90 \pm 0.58$ & $0.90 \pm 0.08$ & $0.97 \pm 0.23$ & 0.647 & \\
\hline Body fat percentage & $36.6 \pm 9.19$ & $38.0 \pm 9.10$ & $38.8 \pm 13.3$ & $\mathbf{0 . 0 3 0}^{\mathrm{a}}$ & $1^{\mathrm{a}}$ \\
\hline Muscle mass & $27.2 \pm 6.92$ & $28.3 \pm 9.19$ & $26.9 \pm 10.3$ & 0.174 & \\
\hline Visceral fat & $8.60 \pm 4.68$ & $9.78 \pm 4.43$ & $10.3 \pm 3.90$ & 0.001 & 1,2 \\
\hline SAT $(\mathrm{mmHg})$ & $118.3 \pm 20.0$ & $122.9 \pm 21.8$ & $121.4 \pm 16.9$ & 0.011 & 1 \\
\hline DAT $(\mathrm{mmHg})$ & $80.4 \pm 11.4$ & $82.0 \pm 13.6$ & $80.1 \pm 12.1$ & 0.181 & \\
\hline Glucose $(\mathrm{mg} / \mathrm{dL})$ & $98.8 \pm 38.9$ & $113.1 \pm 53.0$ & $124.4 \pm 60.8$ & $<0.001^{a}$ & $1^{\mathrm{a}}, 2^{\mathrm{a}}$ \\
\hline Triglycerides $(\mathrm{mg} / \mathrm{dL})$ & $144.9 \pm 110.7$ & $173.4 \pm 98.1$ & $179.3 \pm 103.2$ & $<0.001$ & 1 \\
\hline Total cholesterol (mg/dL) & $190.8 \pm 39.5$ & $201.3 \pm 39.5$ & $200.2 \pm 45.3$ & 0.001 & 1 \\
\hline HDL $(\mathrm{mg} / \mathrm{dL})$ & $55.3 \pm 13.6$ & $51.8 \pm 17.3$ & $49.1 \pm 13.9$ & 0.008 & 1 \\
\hline $\mathrm{LDL}(\mathrm{mg} / \mathrm{dL})$ & $104.2 \pm 32.4$ & $117.9 \pm 39.9$ & $94.1 \pm 41.7$ & $<0.001^{a}$ & $1^{\mathrm{a}}, 3^{\mathrm{a}}$ \\
\hline VLDL (mg/dL) & $26.6 \pm 13.6$ & $34.4 \pm 19.5$ & $39.1 \pm 22.5$ & $<0.001^{a}$ & $1^{\mathrm{a}}, 2^{\mathrm{a}}$ \\
\hline Uric acid $(\mathrm{mg} / \mathrm{dL})$ & $5.3 \pm 1.5$ & $5.62 \pm 1.2$ & $6.0 \pm 1.2$ & 0.658 & \\
\hline Creatinine $(\mathrm{mg} / \mathrm{dL})$ & $0.71 \pm 0.25$ & $0.73 \pm 0.25$ & $0.65 \pm 0.19$ & 0.251 & \\
\hline ALT (IU/L) & $19.2 \pm 13.0$ & $23.1 \pm 13.2$ & $28.8 \pm 12.1$ & 0.005 & 1,2 \\
\hline AST (IU/L) & $23.2 \pm 8.60$ & $27.8 \pm 11.6$ & $24.5 \pm 7.11$ & $0.024^{\mathrm{a}}$ & $1^{\mathrm{a}}$ \\
\hline T/G index, Ln & $4.68 \pm 0.33$ & $4.84 \pm 0.34$ & $4.87 \pm 0.45$ & $<0.001^{\mathrm{a}}$ & $1^{\mathrm{a}}, 2^{\mathrm{a}}$ \\
\hline
\end{tabular}

$p<0.001$ in bold means 0.000 value.

${ }^{a}$ Kruskal-Wallis test and Mann-Whitney U test.

1, comparison AA with A/G genotypes; 2 comparison A/A with $\mathrm{G} / \mathrm{G}$ genotypes; 3 comparison A/G with G/G genotypes; P, probability with a confidence of $95 \%$. 


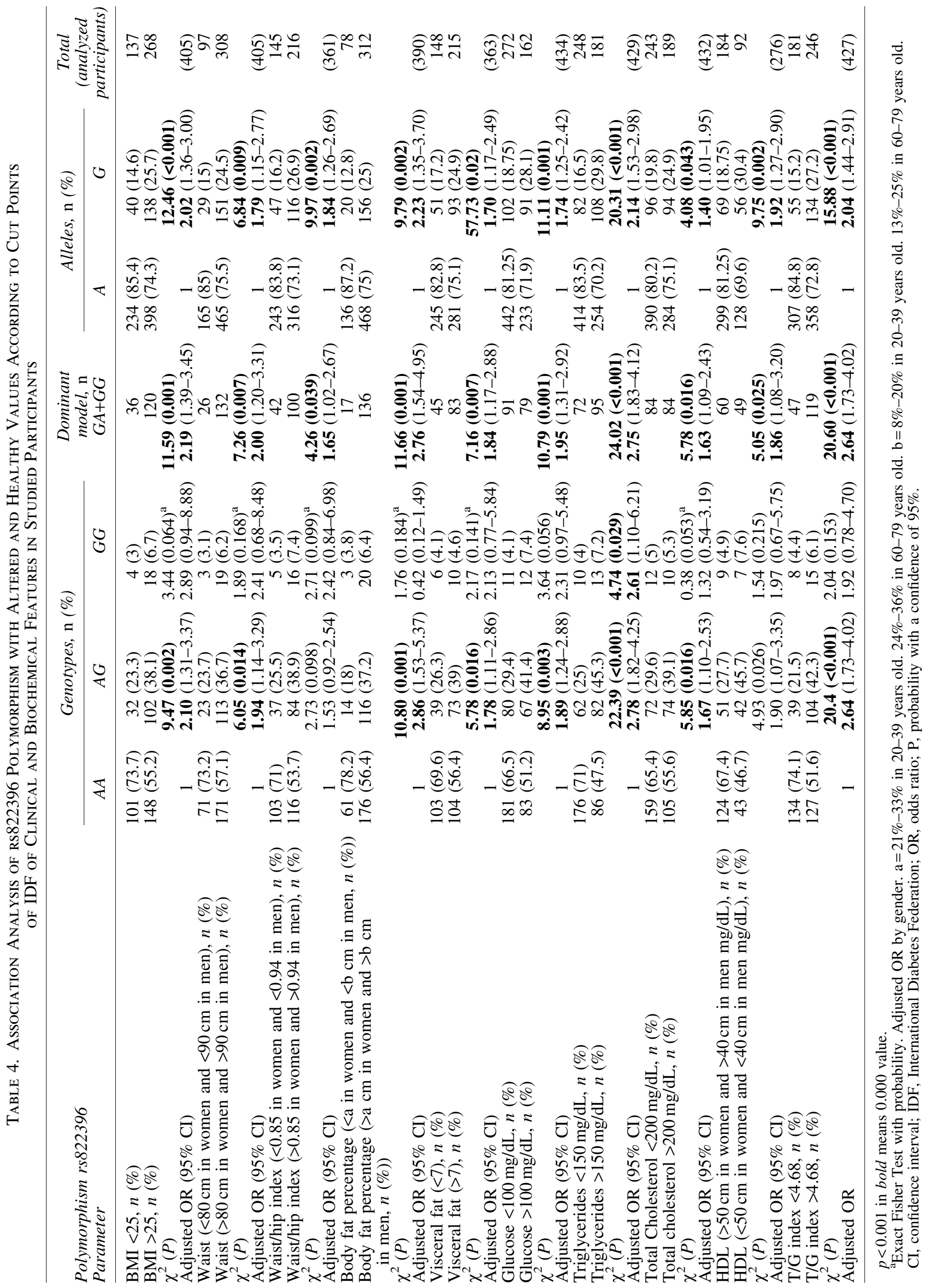


the anthropometric, clinical, and biochemical alterations related to the metabolic syndrome in the Mexican population.

\section{Population description}

The frequency of clinical and biochemical parameters in the individuals is according to ENSANUT (the project describes the nutritional conditions and health state of the Mexican population) except in abdominal obesity and TC (47\% and $28 \%$, respectively). ${ }^{18}$

According to the IDF, one in four individuals has metabolic syndrome worldwide. ${ }^{11}$ Of the total participants of this study, $30.4 \%$ meet the IDF diagnostic criteria for metabolic syndrome. The last may be due to the lifestyle and obesity prevalence, where, according to the Organization for Economic Co-operation and Development, Mexico in 2017 reported that $32.4 \%$ of the people older than 15 years old have obesity, occupying the second position worldwide. ${ }^{19}$

Expected differences by gender were found in the anthropometric, clinical (including visceral fat and blood pressure), and biochemical factors (HDL in addition to TC, uric acid, creatinine, and ALT). IR is directly related to the glucose alteration and previously described with the triglyceride participation. ${ }^{9}$ The T/G index correlates with HOMA index to determinate IR. ${ }^{20}$ This study found a high rate of IR represented in 6 of each 10 individuals, particularly in men.

\section{Frequency of polymorphism rs822396 of ADIPOQ gene}

The frequency of the rs822396 polymorphism in the $A D I P O Q$ gene in this work was for GG genotype $5.3 \%$ and the $\mathrm{G}$ allele $22.1 \%$. According to 1000 Genomes, in a Mexican population resident of Los Angeles, United States, the GG genotype was not detected, but AG genotype frequency was $28 \%$ and allele $\mathrm{G}$ was $14 \% .^{21}$ In this study, the $\mathrm{G}$ allele was observed with $8.1 \%$ more frequency of reported 1000 genomes; this last observation is due to the presence of GG genotypes in participants of this study. In addition, from reports of this polymorphism, associated with components of metabolic syndrome, the frequency for controls of GG genotype in Chennai population (India) was $10.4 \%,{ }^{6}$ in Punjab population (North of India) reported $8.9 \%,{ }^{22}$ and in the Tunisia population (Arabia) a $9.7 \%,{ }^{7}$ which represents twice the frequency of the observed in this study. These last studies showed at least $4 \%$ more frequency of GG genotype than the present study. The differences observed of the frequencies in this study with regard to other populations could be due to the genetic background of each region.

\section{Contribution of rs822396 polymorphism to metabolic alteration}

The means of the clinical and biochemical features were separated according to rs822396 genotype. A rise in mean with statistical differences was observed in participant carriers of GG genotype in parameters such as BMI, WC, body fat percentage, visceral fat, SAT, and levels of glucose, triglycerides, TC, HDL, VLDL, LDL, ALT, and AST in addition to IR surrogated.

There are reports of the association of the GG genotype of rs822396 polymorphism with obesity. ${ }^{6,22}$ In this study it was observed that $G$ allele could contribute to overweight or obesity since the AG and GG carriers had a higher average of BMI, WC, body fat percentage, and visceral fat. The adipose tissue is an endocrine organ but, when obesity is present, drops their stable metabolic function that leads to a disequilibrium in metabolic and biochemical processes. The environmental change of adipose tissue in obesity twists from normal metabolic function to complete metabolic dysfunction in obese individuals and could lead to a low-grade chronic inflammation. ${ }^{13}$ The averages of glucose, lipid profile, and hepatic enzymes were altered in AG and GG carriers, in addition to IR existence. This observation can be explained because ApN can activate adenosine monophosphate (AMP)activated protein kinase (AMPK) to favor the GLUT4 translocation that transports glucose into the cells, block Malonyl CoA to avoid inactivation of $\beta$-oxidation, and reduce the triglyceride and fatty acid formation. As well AMPK can block transcription of Sterol regulatory element-binding protein 1 (SREBP-1C) that contributes to decrease the fat acid levels. ${ }^{14}$ The AG and GG carriers could decrease the transcriptional activity of ApN altering the last mechanisms.

\section{Association analysis of rs822396 polymorphism}

The participants with a genotype carrying the $\mathrm{G}$ allele (dominant model and allele) had a twofold risk for overweight and obesity presentation. Previously, the GG genotype was associated with obesity manifested by alterations in the BMI, WC, waist/hip ratio, waist/height ratio (OR of $1.52),{ }^{22}$ as well as for overweight and obesity in DM2 patients (OR of 1.38). ${ }^{6}$ In addition, other parameters related to obesity and cardiovascular diseases ${ }^{23}$ (WC, waist/hip index, body percentage fat, and visceral fat) showed a risk around twofold for $G$ allele carriers (AG genotype, dominant model, and G allele).

In the participants of this study, risk of 1.74-fold for impaired glucose levels in carriers of $\mathrm{G}$ genotypes or allele (AG genotype, dominant model, and $\mathrm{G}$ allele) was observed. The impaired glucose levels were observed in DM patients, as well as individuals with metabolic syndrome, as a component of the disease. The GG genotype was previously reported associated with DM2 cases (OR of 1.56$)^{6}$ and to metabolic syndrome susceptibility (OR of 1.45). ${ }^{22}$

Moreover, with regard to altered lipid profile (triglycerides, HDL, and TC) a risk between 1.40- and 2.78-fold for G allele carriers (AG and GG genotype, dominant model, and G allele) was observed in this study. Previous reports have associated the GG genotype with both elevated TC and triglyceride levels (OR of 1.52). ${ }^{22}$

Finally, it was found that the heterozygous participants and the dominant model have a 2.64-fold risk and for the allele G an OR of 2.04, to exhibit IR. The IR is observed in diabetes or previous states of diabetes.

The association of the polymorphism rs 822396 with obesity, impaired glucose, lipid profile altered, and the presence of IR can be explained by the generation of miRNAs or alternative splices resulting from the change in the polymorphic site and, on the other hand, the presence of intronic amplifiers: both mechanisms could be associated with the modification of serum levels or transcript rates ${ }^{16,24-26}$ or the reduction of $\mathrm{ApN}$ by transcriptional or translational regulation. Since rs 822396 polymorphism is located nearby to a response element to the C/EBP factor, it could modify the $A D I P O Q$ transcription rate; however, this must be studied. 
There are studies of serum ApN level measurement to determine its correlation with the rs822396 polymorphism, where correlation ${ }^{6}$ and no correlation ${ }^{15}$ are showed but serum levels were not measured in the present study. The serum ApN levels could be evaluated by measurement of total ApN or multimeric ApN. In this work, serum ApN levels were not measured because the serum samples were collected for biochemical determinations. In addition, it could be necessary to analyze the transcript levels instead of serum levels, to have more evidence of the reduction of ApN by transcriptional regulation. In addition, it was described that two functional polymorphisms are in linkage disequilibrium, the $+2019 \mathrm{~A} /-$ insertion/deletion polymorphism located at $3^{\prime}$ region and the rs2241766 in exon 2; those polymorphisms contribute to transcriptional regulation. Furthermore, the rs822396 polymorphism is in linkage disequilibrium with rs2241766. ${ }^{15}$ It is necessary to determine linkage disequilibrium with other single nucleotide polymorphism (SNPs) in the Mexican population to confirm this previous observation.

The present study had limits, including a small sample size despite the statistical power. Otherwise, in this study the serum ApN levels were not determined; it is recommended to measure total and multimeric ApN levels and also the transcriptional level of $A D I P O Q$, to estimate the participation of rs822396 in transcriptional or transduction regulation.

\section{Conclusions}

The genotypes carrying $G$ allele (and this one) of the rs822396 polymorphism were associated with obesity, impaired glucose, lipid profile altered, and IR. The rs822396 polymorphism of $A D I P O Q$ can be a candidate susceptibility marker for obesity and alteration in metabolic parameters that could lead to chronic metabolic diseases in the Mexican population as the Metabolic syndrome.

\section{Acknowledgment}

The authors acknowledge the Universidad de Guadalajara for invaluable support to perform this work.

\section{Author Disclosure Statement}

No conflicting financial interests exist.

\section{Funding Information}

This work was funded by PROSN1 number 248576/ 11482, Universidad de Guadalajara.

\section{References}

1. Choe SS, Huh JY, Hwang IJ, et al. Adipose tissue remodeling: Its role in energy metabolism and metabolic disorders. Front Endocrinol (Lausanne) 2016;7:30.

2. Scherer PE, Williams S, Fogliano M, et al. A novel serum protein similar to $\mathrm{C} 1 \mathrm{q}$, produced exclusively in adipocytes. J Biol Chem 1995;270:26746-26749.

3. Yamauchi T, Kamon J, Waki H, et al. The fat-derived hormone adiponectin reverses insulin resistance associated with both lipoatrophy and obesity. Nat Med 2001;7:941-946.

4. Breitfeld J, Stumvoll M, Kovacs P. Genetics of adiponectin. Biochimie 2012;94:2157-2163.
5. Vasseur F, Helbecque N, Dina C, et al. Single nucleotide polymorphism haplotypes in the both proximal promoter and exon 3 of the APM1 gene modulate adipocyte-secreted adiponectin hormone levels and contribute to the genetic risk for type 2 diabetes in French Caucasians. Hum Mol Genet 2002;11:2607-2614.

6. Ramya K, Ayyappa KA, Ghosh S, et al. Genetic association of ADIPOQ gene variants with type 2 diabetes, obesity and serum adiponectin levels in south Indian population. Gene 2013;532:253-262.

7. Mtiraoui N, Ezzidi I, Turki A, et al. Single-nucleotide polymorphisms and haplotypes in the adiponectin gene contribute to the genetic risk for type 2 diabetes in Tunisian Arabs. Diabetes Res Clin Pract 2012;97:290-297.

8. Reddy SM, Sadim M, Li J, et al. Clinical and genetic predictors of weight gain in patients diagnosed with breast cancer. Br J Cancer 2013;109:872-881.

9. Simental-Mendía LE, Rodríguez-Morán M, GuerreroRomero F. The product of fasting glucose and triglycerides as surrogate for identifying insulin resistance in apparently healthy subjects. Metab Syndr Relat Disord 2008;6:299-304.

10. Miller SA, Dykes DD, Polesky HF. A simple salting out procedure for extracting DNA from human nucleated cells. Nucleic Acids Res 1988;16:1215.

11. International Diabetes Federation. The IDF consensus worldwide definition of the metabolic syndrome. Available at file:///C:/Users/CUCS/Downloads/IDF_Meta_def_final .pdf Accessed on April 2019.

12. National Institute of Statistics and Geography. Press release num 525/18. Characteristics of deaths recorded in Mexico during 2017. Available at www.beta.inegi.org.mx/contenidos/ saladeprensa/boletines/2018/EstSociodemo/DEFUNCIONES 2017.pdf Accessed on April 2019.

13. Ouchi N, Parker JL, Lugus JJ, et al. Adipokines in inflammation and metabolic disease. Nat Rev Immunol 2011; 11:85-97.

14. Polyzos SA, Kountouras J, Mantzoros CS. Adipokines in nonalcoholic fatty liver disease. Metabolism 2016;65: 1062-1079.

15. Pollin TI, Tanner K, O'Connell JR, et al. Linkage of plasma adiponectin levels to $3 \mathrm{q} 27$ explained by association with variation in the APM1 gene. Diabetes 2005;54:268-274.

16. Wakai K, Matsuo K, Matsuda F, et al. Genome-wide association study of genetic factors related to confectionery intake: Potential roles of the ADIPOQ gene. Obesity (Silver Spring) 2013;21:2413-2419.

17. Li Q, Ma Y, Sang W, et al. Five common haplotypetagging variants of adiponectin (ADIPOQ) and cancer susceptibility: A meta-analysis. Genet Test Mol Biomarkers 2014;18:417-424.

18. Hernandez Avila M, Rivera Dommarco J, Shaman tevy T, et al. Health Secretary, Final report of the results of the national half-way health and nutrition survey 2016. Available at http://transparencia.insp.mx/2017/auditoriasinsp/12701_Resultados_Encuesta_ENSANUT_MC2016.pdf Accessed on April 2019.

19. Organization for Economic Co-operation and Development (OCDE). Obesity Update 2017. Available at www.oecd .org/health/health-systems/Obesity-Update-2017.pdf Accessed on April 2019.

20. Guerrero-Romero F, Simental-Mendía LE, González-Ortiz $\mathrm{M}$, et al. The product of triglycerides and glucose, a simple measure of insulin sensitivity. Comparison with the euglycemic-hyperinsulinemic clamp. J Clin Endocrinol Metab 2010;95:3347-3351. 
21. 1000 Genomes. A deep catalog of human genetic variation. Available at http://phase3browser.1000genomes.org/Homo_ sapiens/Variation/Population?r=3:186566377-186567377; $\mathrm{v}=\mathrm{rs} 822396 ; \mathrm{vdb}=$ variation; $\mathrm{vf}=577137$ Accessed on April 2019.

22. Kaur H, Badaruddoza B, Bains V, et al. Genetic association of ADIPOQ gene variants $(-3971 \mathrm{~A}>\mathrm{G}$ and $+276 \mathrm{G}>\mathrm{T})$ with obesity and metabolic syndrome in North Indian Punjabi population. PLoS One 2018;13:e0204502.

23. Mohammadifard N, Nazem M, Sarrafzadegan N, et al. Body mass index, waist-circumference and cardiovascular disease risk factors in Iranian adults: Isfahan healthy heart program. J Health Popul Nutr 2013;31:388-397.

24. Ying SY, Lin SL. Intron-derived microRNAs-Fine tuning of gene functions. Gene 2004;342:25-28.

25. Menzaghi C, Trischitta V, Doria A. Genetic influences of adiponectin on insulin resistance, type 2 diabetes, and cardiovascular disease. Diabetes 2007;56:1198-1209.

26. Wassel CL, Pankow JS, Jacobs DR Jr, et al. Variants in the adiponectin gene and serum adiponectin: The coronary artery development in young adults (CARDIA) study. Obesity (Silver Spring) 2010;18:2333-2338.

Address correspondence to: Susan Andrea Gutierrez-Rubio, PhD Laboratorio del Instituto de Terapeutica Experimental y Clinica Departamento de Fisiologia Centro Universitario de Ciencias de la Salud Universidad de Guadalajara Sierra Mojada 950, Edificio P primer Nivel Col Independencia, CP 44340 Guadalajara Jalisco México

E-mail: susan.gutierrez@academicos.udg.mx 